The research program of the Center for Economic Studies produces a wide range of theoretical and empirical economic analyses that serve to improve the statistical programs of the U.S. Bureau of the Census. Many of these analyses take the form of research papers. The purpose of the Discussion Papers is to circulate intermediate and final results of this research among interested readers within and outside the Census Bureau. The opinions and conclusions expressed in the papers are those of the authors and do not necessarily represent those of the U.S. Bureau of the Census. All papers are screened to ensure that they do not disclose confidential information. Persons who wish to obtain a copy of the paper, submit comments about the paper, or obtain general information about the series should contact sang V. Nguyen, Editor, Discussion Papers, Center for Economic Studies, Room 1587, FB 3, U.S. Bureau of the Census, Washington, DC 20233-6300, (301-763-2065).

\title{
LEARNING BY DOING AND COMPETITION IN THE EARLY RAYON INDUSTRY
}

\author{
By \\ Ronald S. Jarmin* \\ CES 93-4 February 1993
}




\section{Abstract}

In this paper, I derive a structural econometric model of learning by doing from a dynamic oligopoly game. Unlike previous empirical models, this model is capable of testing hypotheses concerning both the technological nature and behavioral implications of learning. I estimate the model with firm level data from the early U.S. rayon industry. The empirical results show that there were considerable differences across firms in both proprietary and spillover learning. The results also indicate that two of the three firms took their rival's reactions into account when choosing their strategies.

Keywords: learning by doing, spillovers, rayon industry

${ }^{*}$ Center for Economic Studies, U. S. Bureau of the Census

This paper is a revised version of a chapter from my Ph.D dissertation at the University of Oregon. I would like to thank Jim Adams, Van Kolpin, Daniel McMillen, Mark Roberts, Ken Troske and Wesley Wilson for helpful comments. Any opinions, findings 
or conclusions expressed here are those of the author and do not necessarily reflect the views of the Census Bureau. 


\section{I . INTRODUCTION}

Learning by doing introduces an intertemporal dimension to a firm's output strategy. Current production adds to the firm's stock of experience. Increases in the firm's stock of experience lower its unit costs in future periods. If the firm's experience is completely proprietary, its optimal strategy is to overproduce in early periods in order to invest in future cost reduction. This suggests that incumbent firms can exploit the learning curve to gain an absolute cost advantage over potential entrants and erect entry barriers. However, the incentive to overproduce diminishes if the firm's rivals learn from its experience via spillovers. ${ }^{1}$

Numerous empirical studies have documented the existence of learning by doing in several industries. ${ }^{2}$ Importantly, some studies find that spillover learning accounts for a larger proportion of cost reduction than proprietary learning. This suggests that the effectiveness of the learning curve for deterring entry may be limited in actual industries. However, there are two important shortcomings in the empirical literature on learning by doing.

First, authors invariably assume that spillover benefits accrue to firms in an industry equally. In the next section, I discuss several reasons why it is unlikely that this would occur in actual industries. Imposing spillover symmetry has two 
disadvantages. The first is that a lot of potentially interesting information about the pattern of learning in the industry is lost. The second is more problematic. In many cases, cost data with which to estimate learning parameters are not available. A solution used in some previous studies is to assume that price-cost margins are constant over time and use price as a proxy for unit costs in learning regressions. If experience is a pure public good, theory suggests this assumption is appropriate. If not, the relationship between unit costs and price is unclear. In this case, the researcher must model the process that generated the observed market prices before drawing any inferences about the nature of learning in the industry.

The second shortcoming in the existing empirical literature is the failure of authors to examine the behavioral implications of learning. Theoretical research shows that learning has important consequences for firm behavior. However, there is no empirical evidence with which to answer the question; do firms take the dynamic effects of learning into account when choosing their output strategies? The answer has important consequences for how economists model learning by doing.

To overcome these shortcomings, I construct a structural model of dynamic nonprice competition which incorporates learning by doing. I estimate the model with firm level data from the early U.S. rayon industry. The framework employed is similar to that used by Roberts and Samuelson (1988) to examine advertising 
in the cigarette industry. The model extends the growing empirical literature in industrial organization that

seeks to explain competition in oligopolistic industries (see Bresnahan [1989] and Geroski [1988] for reviews of this literature) .

In the next section, I review some background issues. In section III, I briefly discuss some important features of the early rayon industry that aid in constructing the model in section IV. In section V, I discuss the data and estimation procedure. The estimation results are provided in section VI. Finally, summary and conclusions are given in section VII.

\section{BACKGROUND}

In his seminal paper, Wright (1936) employed the now common log-linear specification of the learning curve with cumulative production as his index of experience to examine airframe production. He found a significant negative relationship between average direct man-hour costs and the cumulative number of airframes produced. Subsequent authors from diverse disciplines have tested the reliability and generality of Wright's findings. Important contributions in the economics literature include Alchian (1963), Rapping (1965) and Sheshinski (1967). The work of the Boston Consulting Group in the early 1970's did much to popularize the concept of learning by doing 
More recently, Lieberman (1982, 1984) examined learning in several chemical processing industries. His findings suggest that these industries experienced significant cost reductions due to learning by doing. Importantly, he reports that spillover learning accounts for a larger share of cost reduction than proprietary learning. Further, his estimates of the slopes of 37 product specific learning curves are very similar, suggesting that the phenomenon of learning by doing is robust across his sample of chemical processing industries.

Lieberman employs a single equation model and adopts the log-linear form of the learning curve. He uses price rather than cost as the dependent variable in his econometric model because cost data were not available. For his model to be a valid specification of a learning curve relationship, price-cost margins must remain constant over time. He analyzes a theoretical model similar to spence's (1981), which predicts that when the number of firms and the elasticity of demand are constant over time and experience is a pure public good (i.e., spillovers are complete and symmetric), price will decline at approximately the same rate as marginal cost. When these conditions prevail, price is an acceptable proxy for unit cost in an empirical model of learning by doing. Lieberman exploits his empirical finding that spillover learning is significant to justify the specification of his econometric model. However, since he uses industry level data, he cannot test the assumption 
that spillovers are symmetric.

Jarmin (1992) provides a theoretical model which shows that different spillover scenarios have different implications for firm behavior and market performance. In particular, when there are no spillovers or when firms benefit from spillovers asymmetrically, price-cost margins will not remain constant over time. It is unlikely that a given industry (or group of industries as in Lieberman's case) will be characterized by the special case of complete and symmetric spillovers. Geographical location, research and development expenditures, employee training programs and other idiosyncratic firm characteristics are likely to affect the ability of firms to benefit from the experience of their rivals. An empirical model that allows margins to vary over time is, therefore, better suited for testing hypotheses concerning the existence and implications of learning by doing in an industry.

\section{THE AMERICAN RAYON INDUSTRY: 1911-1938}

In this section, I briefly describe the American rayon industry from its beginning to the years just preceding the second world war. In this discussion, I focus on several important structural and behavioral characteristics of the industry. I later exploit these characteristics to formulate a model of the industry. Avram (1929), U.S. Tariff Commission (1944), Markham (1952) and Coleman (1969) provide more detailed 
analyses of the industry.

\section{A. Structural Features of the Early Rayon Industry}

Rayon is the generic term describing synthetic textile fibers produced from cellulose. Rayon was the first synthetic textile fiber developed and put into commercial production. For several years, the public (and textile mill operators) viewed rayon as an inferior silk substitute. But as quality improved and textile producers became more aware of its possibilities, uses of rayon grew to include numerous woven and knitted textile fabrics, tire cord, and innumerable specialty items and novelty goods.

The American Viscose Company (A.V.C.) commenced rayon production in 1911. It was the sole U.S. rayon manufacturer until 1920 and remained the largest American producer throughout the period under study. ${ }^{3}$ By 1938, 29 firms were manufacturing rayon in the United States. However, the industry remained highly concentrated, with the 8 largest firms accounting for 91\% of production in 1938." Table 1 lists 1, 2, 3 and 8 firm concentration ratios for selected years. During the 1911-1938 period, the two largest firms (A.V.C. and DuPont) never accounted for less than half of U.S. rayon production and the market share of the smallest 21 firms never exceeded $10 \%$

The rayon industry is often cited as an example of a homogeneous good oligopoly. Markham (1952, p.1) states that during the period under study ". . rayon output more closely 
approximated homogeneity than does the output of most large industries in the American economy." The output of rayon manufacturers consisted solely of rayon yarn until the development of staple fiber in 1928. Although staple fiber production would take off during World War II, it accounted for only 10\% of rayon output by 1938. Rayon yarn was, therefore, the primary output of rayon producers during the 1911-1938 period. Also, it was standard practice in the industry to convert yarns of varying sizes and strengths to a common yarn to facilitate market analysis. The trade press published price and output data for this standardized yarn.

Learning by doing is likely to be most important in the early stages of an industry's development. Although they perform no formal econometric tests, previous authors suggest that learning by doing was an important feature of the early rayon industry. Hollander (1965) argues that reductions in unit costs at Dupont rayon plants were largely the result of "minor technical changes." This observation is consistent with the process of learning by doing. Using accounting data, Coleman (1969, p.292) graphs the evolution of unit costs for A.V.C. and DuPont from 1921 to 1938. The result looks much like a learning curve.

It appears, however, that the learning curve did not provide substantial barriers to entry in the early rayon industry. This suggests that the benefits of an individual rayon producer's 
experience likely spilled over to rival or potential rival firms. Significant spillover learning is consistent with the existence of several channels through which information could have flowed between rayon producers. These included the close geographical proximity of rayon firms, several trade associations and publications and the affiliations most American producers had with members of the European rayon cartel. ${ }^{5}$

\section{B. Behavioral Features of the Rayon Industry}

The pricing behavior of American rayon producers between 1911 and 1938 was remarkably consistent. Changes in list price were almost always initiated by one of the large firms (namely, A.V.C. or DuPont) and followed quickly by the other firms in the industry. Markham (1952, p. 69) cites several examples of statements made in the trade and government literatures which indicate "that the modus operandi in the rayon industry is one of price leadership." He argues that the acceptance of this relationship was aided by the ease with which information flowed between rayon producers. Also, list prices tended to remain stable over considerable lengths of time. This was part of an overall industry strategy to compete against rival textile fibers (particularly silk which exhibited highly volatile price behavior), rather than against themselves.

Rayon producers did not appear to engage in vigorous inter- 
firm nonprice competition. Rather, they employed strategic variables, such as advertising and research and development, in a joint effort, to compete against rival textile fibers. According to Markham,

Early consumer resistance to a synthetic substitute for silk and cotton, attributable in part to adverse publicity, provided rayon producers with a common enemy. By the late twenties they had jointly launched several organizations and associations for purposes of advertising, chemical research, and promulgation of information of interest to the industry. Such common interests could not be best served by complete arms' length competition [1952, p.3].

Promotional activities were generally intended to have industry wide rather than firm specific effects. Furthermore, due to the similarity in the price and quality of rayon yarn offered by the various producers, advertising probably would have been an ineffective tool of inter-firm competition. Finally, the close proximity of the rayon firms and the well developed industry press and trade associations likely made it difficult for individual producers to appropriate all the benefits of their research and development activities.

\section{EMPIRICAL MODEL OF THE RAYON INDUSTRY}

The last section suggests a strategy for modelling the early U.S. rayon industry. First, from the discussion of its structural features, it is reasonable to model the rayon industry as an oligopoly for a homogeneous product. The behavioral features of the industry suggest that rayon producers did not 
engage in vigorous inter-firm price competition. Nor did they appear to compete against each other via nonprice variables such as advertising or research and development. Instead, rayon producers employed pricing, advertising and research strategies jointly to position the industry more advantageously against competing textile fibers such as silk, cotton and wool. Finally, early rayon producers likely benefitted from learning by doing . Therefore, for modelling purposes, I assume the rayon industry is an oligopoly for a homogeneous good in which firms engage in quantity competition. Further, I assume that output strategies have intertemporal effects via learning by doing.

Unlike the reduced form model employed by Lieberman the structural model described below requires no restrictions on the nature of the price-cost margins. I derive pricing relations directly from a dynamic theoretical oligopoly model. These contain expressions for marginal cost which are sufficiently general to test for spillover learning and whether learning benefits accrue to firms symmetrically as assumed in previous studies.

\section{A. Theoretical Model}

Competition in an industry characterized by learning by doing can be modelled as a dynamic game. Assume that there are $\mathrm{n}$ firms and $\mathrm{T}$ discrete time periods. At the beginning of each period, firms choose quantities of a homogeneous output, $q_{i t}$. 
Firm i's costs in period $t, C_{i t}\left(q_{i t}, w_{i t}, x_{t}\right)$, are a function of current output, input prices and the experience vector, $x_{t}$. In this paper, I index experience with cumulative production. Thus, firm i's stock of experience at time $t$ is $x_{i t}={ }^{\prime}{ }_{s=1}^{t} q_{i s}$ which yields the industry experience vector $x_{t}=\left(x_{i t}\right)_{i=1}^{n}$. Output choices play an additional role as investments in experience. The more output produced today, the lower unit costs will be tomorrow. The objective of each firm is to choose values of $q_{i t}$ to maximize

$$
\begin{gathered}
\Pi_{i}=\sum_{t=1}^{T} \delta^{t-1}\left\{P\left(q_{t}\right) q_{i t}-C_{i t}\left(q_{i t}, W_{i t}, X_{t}\right)\right\} \\
\text { s.t. } \quad X_{t}=X_{t-1}+Q_{t-1}
\end{gathered}
$$

$$
x_{0}=0
$$

where $q_{t}={ }^{\prime}{ }_{i=1}^{n} q_{i t}$ is industry output, $Q_{t-1}=\left(q_{i t-1}\right)_{i=1}^{n}$ is the industry output vector and $P\left(q_{t}\right)$ is the industry inverse demand function. The term * is a discount factor.

If firms move simultaneously à la Cournot, the necessary conditions for a closed-loop Nash equilibrium are

$$
\begin{gathered}
\frac{\partial \Pi_{i}}{\partial q_{i t}}=\left\{P_{t}+\frac{\partial P_{t}}{\partial q_{i t}} q_{i t}-\frac{\partial C_{i t}}{\partial q_{i t}}-\sum_{s=t+1}^{T} \delta^{s-t} \frac{\partial C_{i s}}{\partial q_{i t}}+\right. \\
\sum_{s=t+1}^{T} \delta^{s-t}\left\{\frac{\partial P_{s}}{\partial Q_{s}} q_{i s} \sum_{j \neq i} \frac{\partial q_{j s}}{\partial q_{i t}}-\delta \sum_{j \neq i} \frac{\partial C_{i s+1}}{\partial X_{j s+1}} \frac{\partial q_{j s}}{\partial q_{i t}}=0\right.
\end{gathered}
$$

for all $i=1, \ldots, n$ and $t=1, \ldots, \mathrm{T}$. The first term in brackets 
is the standard first order condition from the "static" problem with no learning. Learning by doing, however, creates an explicit intertemporal link between the strategies firms employ today and the competitive environment in which they find themselves tomorrow. The first line of (3) gives the direct effect of the firm's output choices on its payoffs. The second line shows the strategic effect. This arises from the intertemporal nature of the strategies due to learning by doing. When learning is proprietary, $q_{i t}$ and $q_{j s}(s>t$ and $j . . i)$ will be strategic substitutes and incumbent firms may, by overinvesting in experience, erect entry barriers (see Tirole [1988] and Spence [1981]). ${ }^{6}$ Spillovers imply that $q_{i t}$ and $q_{j s}$ will be strategic complements and that the ability of incumbents to deter entry by accumulating experience is reduced.

\section{B. Econometric Specification}

The empirical model of the rayon industry consists of pricing relations for each firm based on (3) and a demand equation. Structure must be placed on the demand and cost functions (cost parameters are embedded in the pricing relations), and econometric error terms introduced before the model can be estimated.

The parameters of the demand function are not the principal interest of this study. However, the elasticity of demand plays an important role in the pricing relations. I specify the 
inverse demand function as

$$
\ln P\left(g_{t}, Y_{t}\right) \approx \alpha_{0}+\eta_{q} \ln q_{t}+\sum_{k} \eta_{k} \ln y_{k t}+\eta_{\tau} t
$$

where "o, $0_{q}, 0_{k}$ and $0_{\text {J }}$ are parameters to be estimated. The $m$ vector $Y_{t}=\left(y_{k t}\right)_{k=1}^{m}$ contains nonprice demand determinants. Given (4), the expression $\mathbb{P}_{t} / \mathbb{M}_{t}$ in (3) can now be written as $0_{q}\left(P_{t} / q_{t}\right)$. The empirical pricing relations require expressions for marginal cost. These expressions include parameters which measure learning. However, learning by doing refers to the negative relationship between experience and average costs. To ensure that the learning parameters can be interpreted as such, I assume constant instantaneous returns to scale so that marginal and average cost are the same. I later test and fail to reject the restriction of constant returns to scale for firms in the early rayon industry.

I approximate marginal cost as

$$
\frac{\partial C_{i t}}{\partial q_{i t}} \approx \hat{\alpha}_{i}+\sum_{h} \alpha_{h}^{i} W_{h t}+\sum_{j}\left[\alpha_{j}^{i} x_{j t}+Y_{j j}^{i}\left(x_{j t}\right)^{2}\right]
$$

for $i, j=1, \ldots, n$ and $t=1, \ldots$. T. This is a second order Taylor series approximation with all the second order terms except the $\left({ }_{j j}^{i}\right.$ 's dropped. The $\mathrm{w}_{\mathrm{ht}}$ terms are input prices. Negative first order (" $\left.\begin{array}{c}i \\ j\end{array}\right)$ and positive second order $\left(\left(\begin{array}{l}i j \\ j\end{array}\right)\right.$ learning parameters are consistent with a log-linear type learning curve.

Structure must also be placed on the dynamic effects 
contained in the first order conditions. The model would be overparameterized if all the terms which measure these effects were to be estimated. Following Roberts and Samuelson (1988), I capture all dynamic effects which occur two or more periods into the future via a firm specific constant. ${ }^{7}$ Namely,

$$
\begin{aligned}
\tilde{\alpha}_{i} & =\sum_{s=t+2}^{T} \delta^{(s-t-1)}\left\{\frac{\partial P_{s}}{\partial Q_{s}} q_{i s} \sum_{j \neq i} \frac{\partial q_{j s}}{\partial q_{i t}}-\sum_{j \neq i} \frac{\partial C_{i s}}{\partial x_{j s}} \frac{\partial q_{j s}}{\partial q_{i t}}-\frac{\partial C_{i s}}{\partial q_{i t}} .\right. \\
& I \text { also specify the following behavioral parameter for each }
\end{aligned}
$$
firm

$$
\Theta_{i}-\sum_{j \neq i} \frac{\partial q_{j t+1}}{\partial q_{i t}}
$$

If firm i's rivals learn from its experience and firm i recognizes this and behaves rationally as prescribed in (3), then the expected sign for $1_{i}$ is positive $\left(q_{i t}\right.$ and $q_{j t+1}$ are strategic complements). If its experience is proprietary and firm i behaves rationally, the expected sign for $1_{i}$ is negative ( $q_{i t}$ and $\mathrm{q}_{j t+1}$ are strategic substitutes). If either firm i's experience benefits no one or firm $i$ behaves as if it did not, the estimate of $1_{i}$ should be zero.

I assume that the demand function and the pricing relations have additive econometric disturbance terms. These disturbances model the impact of random events (such as errors in optimization) which affect the decisions of both buyers and sellers in the rayon market but are unobservable to the econometrician. The econometric model of the early rayon 
industry is now written

$$
\begin{gathered}
\ln P_{t}-\alpha_{0}+\eta_{q} \ln q_{t}+\sum_{k} \eta_{k} \ln y_{k t}+\eta_{\tau} t+u_{0} \\
P_{t}+\alpha_{i}+\eta_{q} s_{i t}-\sum_{h} \alpha_{h}^{i} W_{h t}-\sum_{j}\left[\alpha_{j}^{i} x_{j t}+\gamma_{j j}^{i}\left(x_{j t}\right)^{2}\right] \\
-\left[\alpha_{i}^{i}+2 \gamma_{i i}^{i} x_{i t+1}\right] q_{i t+1}+\left[\eta_{d} s_{i t+1}\right] \Theta_{i}-u_{i}
\end{gathered}
$$

for $i, j=1, \ldots n$ and $t=1, \ldots \mathrm{T}$, and where $s_{i t}=P_{t} q_{i t} / q_{t}$. Assume the $n+1$ vector $\left(u_{0}, u_{1}, \ldots, u_{n}\right)$ ' is i.i.d. normal with mean vector zero and $(n+1) \times(n+1)$ covariance matrix '. The parameters " ${ }_{i}$ are composites of the firm specific constants " ${ }_{i}$ and " ${ }_{i}$. Price-cost margins are endogenous in this specification, since I estimate a parameterized expression for marginal costs for each firm. ${ }^{8}$ This is important in industries, such as rayon, where entry puts downward pressure on margins over time.

\section{DATA AND ESTIMATION}

To estimate the model, I have assembled a data set covering the first 28 years (1911-1938) of rayon production in the U.S. ${ }^{9}$ The sample was cut off at 1938 because the World War II seriously disrupted the textile markets, and I could not obtain all the necessary data for any post war years. Furthermore, the importance of learning by doing as a factor in the rayon industry likely diminished by this time. 
In order to examine learning spillovers, firm level measures of experience are necessary. I was able to construct complete output series for A.V.C, DuPont and a composite of the next 6 largest producers, (hereafter referred as Six) ${ }^{10}$. I do not examine the behavior of the small fringe firms. From the firm level output data, I construct the cumulative output variables that serve as learning indices. I obtained price data for two important inputs, wages for production workers and the price of dissolving wood pulp. I assume that firms face the same input prices, because firm level input price data are not available. I include prices of other textile fibers (silk, cotton and wool), GNP and annual automobile registrations, REG, (included as a proxy for tire production) as nonprice demand determinants. Time enters the demand equation as a proxy for rayon quality.

The econometric model is a system of equations, some of which are nonlinear in the parameters. The fact that the elasticity of demand appears in each equation, and the nature of the disturbance terms suggests that the errors will be contemporaneously correlated across equations. Therefore, I estimate the model with non-linear three stage least squares (NL3SLS). The prices of rayon, silk, cotton and wool as well as current and future quantities of rayon output are endogenous. Instrumental variables include lagged values of the endogenous variables, quantities of silk, cotton and wool, total investment for each firm, and firm dummies which indicate whether the firm 
employs one or multiple production methods.

The pricing relations (9) are written in implicit form, so I use the NL3SLS estimator due to Gallant and Jorgenson (1977). To improve efficiency of the final estimates, I iterate the NL3SLS procedure twice. In order to estimate the model, I first estimate the demand equation via two stage least squares and each of the pricing relations via non-linear two stages least squares. The estimated residuals from this procedure are used to compute a consistent initial estimate of the covariance matrix G. Also, the parameter estimates from the first stage are stacked to obtain the initial parameter vector for the Newton iterative algorithm. Once convergence is attained, I recompute the estimate of $G$. This is used, together with the first round NL3SLS parameter estimates, to compute the final NL3SLS estimates.

To test parameter restrictions in this model, I employ the $\mathrm{T}^{0}$ test statistic developed by Gallant and Jorgenson (1979).

This is computed as $T\left(O_{R}-O_{U}\right)$, where $O_{R}$ and $O_{U}$ are the values of the restricted and unrestricted objective functions,

respectively. The test statistic is distributed $\mathrm{P}^{2}$ with degrees of freedom equal to the number of restrictions.

\section{EMPIRICAL RESULTS}

In this section, I focus primarily on the estimates of the pricing relations. But first, a few points about the demand 
equation should be mentioned. Estimates of the demand parameters for the base model (eqs. 8 and 9) are given in table 2. Note first that, except for the coefficient for the price of cotton $\left(0_{c}\right)$, all the parameter estimates are significantly different from zero at the 5\% level. Second, recall that for most of the sample period, consumers viewed rayon as an inferior substitute for silk. Thus, we might expect to see increases in income exerting downward pressure on rayon prices, ceteris paribus. This accounts for the negative coefficient on the estimate of $0_{\mathrm{GNP}}$. I do not have enough data to test whether, as public perceptions of rayon changed over time, the sign on $0_{\mathrm{GNP}}$ becomes positive. The positive coefficient on the estimate of $0_{\text {J }}$ indicates that improvements in quality of rayon increased demand. In order to measure learning directly in this model, it was necessary to assume constant returns to scale. I tested this restriction by estimating an unrestricted model where the expression for marginal cost in the pricing relations is a function of current output. The test fails to reject the hypothesis that the technologies of the 3 firms exhibited

constant returns to scale over the sample period at the 5\% level (the computed test statistic is $\mathrm{T}^{0}=2.084$ with 3 d.f.).

In table 3, the estimates of "i pulp and "i wages for the base model are significant and have the expected sign for each firm. The constant term is not significantly different from zero for 
any firm. Recall, however, that these are composites of the firm specific constants " ${ }_{i}$ and ". They also pick up any firm specific effects contained in the disturbances. Therefore, it is not possible to suggest what algebraic sign they should posses. Now consider the parameters which measure proprietary learning (" ${ }_{i}$ and $\left({ }_{i i}\right.$, where $i=(A . V . C .$, DuPont, Six)). In the base model, no firm has a significant first order proprietary learning parameter, $\left("{ }_{i}\right)$. The estimated second order proprietary learning parameter $\left(\left({ }_{i i}\right)\right.$ is significant and negative for both DuPont and the composite firm, Six. With a zero first order learning terms, the negative second order terms indicate that these firms benefit from their own experience. Significant spillover learning is also indicated for both Dupont and Six. Both the first $\left("{ }_{j}\right)$ and second order $\left(\left({ }_{j j}\right)\right.$ terms are significant and have signs and magnitudes which indicate that the rate of spillover learning diminishes as the firm's rivals accumulate more experience (here and in the tables the subscript $j$ refers to all firms other than i). This is consistent with the well documented log-linear form of the learning curve. The estimated coefficients suggest that DuPont reached the bottom of its spillover learning curve by 1935 (after the cumulative production of its rivals reached 902 million lbs.). The composite firm ceased to benefit from spillover learning in 1933 (after its rivals had produced 647 million lbs. of rayon yarn). 
The strong evidence for spillover learning in the early rayon industry agrees with previous findings that spillovers are more important in several other industries. However, the second order spillover learning term for A.V.C. has the wrong sign. The own and rival cumulative experience variables are highly collinear. Therefore, I estimated the model where A.V.C. learns from spillovers only. The results are listed in tables 4 and 5. These provide evidence that A.V.C. did learn from rival experience during the sample period (both the first and second order terms are significant and have the expected sign). Estimates of the other parameters are very similar to those for the base model. Using the base model as the unrestricted model, the test fails to reject the hypothesis that A.V.C. does not benefit from its own experience at the 5\% level $\left(\mathrm{T}^{0}=4.45 \mathrm{with}\right.$ 2 d.f.).

Some previous empirical models are valid only if price-cost margins are constant. Theory predicts constant margins when spillovers are symmetric. The present econometric specification is capable of testing for asymmetric learning spillovers. To test the hypothesis that all firms in the rayon industry benefit from spillover learning equally, I again use the base model as the unrestricted model. The restricted model has spillover parameters equalized across firms. The computed test statistic is $\mathrm{T}^{0}=33.6$ with $4 \mathrm{~d} . \mathrm{f}$. and, therefore, the hypothesis of symmetric spillovers is rejected at the 5\% level. I also tested 
this restriction for the case where A.V.C. learns from spillovers only and again the above hypothesis is rejected at the 5\% level $\left(\mathrm{T}^{0}=75.11\right.$ with $\left.4 \mathrm{~d} . \mathrm{f}.\right)$. This evidence suggests that imposing spillover symmetry may be inappropriate in empirical studies of learning by doing. Empirical specifications based on such an assumption may produce misleading results.

Similarly, I tested the hypothesis that firms benefitted from their own experience equally. The computed test statistic is 18.19 with $4 \mathrm{~d} . \mathrm{f}$. and the hypothesis of equal own learning is rejected. This and the forgoing results indicate that there were considerable differences in the abilities of rayon producers to benefit from learning by doing. Such heterogeneity has not been found in previous studies because the authors either use aggregate data or impose symmetry a priori.

The estimated behavioral parameters, in both tables 3 and 5, are significant and positive for both DuPont and Six. The positive sign is consistent with the presence of spillovers. This result also shows that both Dupont and the composite of the next 6 largest firms take into account the effects of their current strategies on their rivals' future decisions.

The estimated behavioral parameter for A.V.C. is not significantly different from zero in either tables 3 or 5 . This result is puzzling. Reports that A.V.C. behaved as a dominant industry leader suggest that it was aware of rival reactions. Namely, if A.V.C. was the dominant firm in a cartel like 
arrangement, as well as the first to enter the industry, we would expect it to strategically exploit the learning curve. In the presence of spillovers, this involves taking steps to ensure that its rivals do not benefit from its experience. The estimate of $2_{\text {Avc }}$ in table 3 , suggests this was not the case.

Another interpretation of A.V.C.'s role in the early rayon industry is, however, consistent with the findings here. A.V.C. was the leading producer in the first synthetic fiber industry in the U.S. The survival of the industry and the firms within it required that they quickly improve the product and perfect their production processes, in order to compete effectively with the natural fibers. This suggests that, as an industry, they should move quickly down the learning curve. As the largest producer, A.V.C. may have assumed a larger responsibility for reducing industry wide costs by investing heavily in experience. Realizing this, the smaller firms behave strategically by reducing their output rates to prevent others from free riding on their experience while they free ride on A.V.C.'s experience.

\section{SUMMARY AND CONCLUSIONS}

There are two important shortcomings in the empirical literature on learning by doing. First, spillovers are invariably assumed to benefit all firms in an industry symmetrically. However, the ability of individual firms to learn from rival experience is likely to differ due to firm specific 
characteristics such as location, training programs and research and development expenditures. Second, the empirical literature fails to examine the behavioral implications of learning. In this paper, I develop and estimate an empirical model which addresses these shortcomings.

I derive the structural model presented in the paper from a dynamic oligopoly game. It allows tests of hypotheses concerning both the technological nature and behavioral implications of learning by doing. I estimate the model with firm level data from the early U.S. rayon industry. I find evidence of both proprietary and spillover learning. Also, the ability to learn from both own and rival experience differed across firms.

The estimated behavioral parameters were significant and of the expected sign for 2 of the 3 firms. That is, they were aware of the intertemporal consequences of their strategies and altered their behavior accordingly. Surprisingly, the behavioral coefficient for the "dominant" firm, A.V.C., was not statistically significant. However, when put in the context of the situation faced by the early industry the fact that A.V.C. appeared to have ignored rival reactions makes sense. Namely, the rayon industry was competing against the natural fibers in an effort to get a foothold in the larger textile fiber market. If A.V.C. was focusing its competitive efforts towards increasing rayon's share of the textile fiber market and not its own share of the rayon market, as the discussion in section 3 suggests, 
then this finding is logical. 


\section{APPENDIX}

\section{Rayon Output}

Data on annual U.S. production of rayon yarn are listed in the Textile Economics Bureau's Base Book of Textile Statistics contained in the January 1962 issue of Textile Organon. Market share data for A.V.C., DuPont, Celanese and the next 5 largest firms (Bemberg, Enka, Industrial, North American and Tubize) are provided in the T.N.E.C. (1941). To obtain output variables for A.V.C., DuPont and Six, I multiply the appropriate market share measure by industry output. Cumulative output variables are then computed from these "firm level" output variables. For example, $\mathrm{x}_{\mathrm{AVC}, \mathrm{t}}=\mathrm{E}_{\mathrm{s}=1}^{\mathrm{t}-1} \mathrm{q}_{\mathrm{AVC}, \mathrm{s}}$ and $\mathrm{x}_{-\mathrm{AVC}, \mathrm{t}}=\mathrm{E}_{\mathrm{s}=1}^{\mathrm{t}-1}\left[\mathrm{q}_{\text {DuPont }, \mathrm{s}}+\mathrm{q}_{\mathrm{Six}, \mathrm{s}}\right]$

\section{Fiber Prices}

Average annual list price data for rayon yarn are also obtained from the Base Book in the Textile Organon, as are average market price data for raw silk, cotton and wool.

\section{Input Prices}

Data on the price of dissolving wood pulp for the years 1911-1928 are obtained from the December issues of the Paper Trade Journal, and from the Base Book of the Textile organon for the years 1929-1938. Data on the wages of production workers are taken from the Census of Manufactures. The Census Bureau collected data on payroll and the number of workers for 1909, 1914 and biannually from 1919 on (for the censuses before 1921 rayon wages are included under "chemical not elsewhere 
classified"). The wage variable is computed by dividing payroll by the number of workers. For the omitted years, the wage is computed as the average of the two adjacent censuses.

\section{Natural Fiber Quantities}

Data on the quantities of the natural fibers (silk, cotton and wool) are taken from USDA (1950). These data are for domestic mill consumption of the respective fiber. Investment

Annual data on total investment of the 8 largest rayon producers are given in the T.N.E.C. (1944). The data for these 8 firms, exclusive of A.V.C. and Dupont are summed for each year to obtain an investment series for Six. Nonprice demand determinants

Data on GNP and motor vehicle registration were obtained from the Historical Statistics of the United States, (1957) Bureau of Census. 
TABLE 1: Concentration Ratios and Rayon Output for Selected Years 1918-1938

\begin{tabular}{|c|c|c|c|c|c|c|}
\hline Year & 1918 & 1922 & 1926 & 1930 & 1934 & 1938 \\
\hline CR1 & 100 & 82 & 59 & 42 & 34 & 30 \\
\hline CR2 & 100 & 88 & 76 & 59 & 54 & 52 \\
\hline CR3 & 100 & 88 & 77 & 64 & 65 & 67 \\
\hline CR8 & 100 & 100 & 93 & 90 & 92 & 91 \\
\hline oty. & 5.8 & 24.1 & 62.7 & 127.3 & 208.3 & 257.6 \\
\hline
\end{tabular}


TABLE 2. Demand Parameter Estimates Base Model

(t-statistics in parentheses)

\begin{tabular}{lc}
\hline & \\
\hline Parameter & Estimate \\
\hline${ }^{\prime} 0$ & -84.436 \\
& $(-2.183)$ \\
$0_{\mathrm{q}}$ & -0.733 \\
& $(-22.11)$ \\
$0_{\text {silk }}$ & 0.502 \\
& $(3.499)$ \\
$0_{\mathrm{cotton}}$ & -0.161 \\
& $(-1.126)$ \\
$0_{\text {wool }}$ & 0.807 \\
& $(5.567)$ \\
$0_{\mathrm{GNP}}$ & -0.833 \\
& $(-4.049)$ \\
$0_{\mathrm{REG}}$ & 0.736 \\
$0_{\mathrm{J}}$ & $(6.165)$ \\
& 0.041 \\
& $(1.930)$ \\
\hline
\end{tabular}



TABLE 3. Pricing Relation Parameter Estimates Base Model (t-statistics in parentheses)

\begin{tabular}{|c|c|c|c|}
\hline Parameter & A.V.C. & Dupont & $\operatorname{Six}$ \\
\hline$"{ }_{i}$ & $\begin{array}{l}-0.240 \\
(-2.153)\end{array}$ & $\begin{array}{l}-1.001 \\
(-2.415)\end{array}$ & $\begin{array}{l}-1.652 \\
(-4.853)\end{array}$ \\
\hline "i pulp & $(3.082)^{0.26 \mathrm{E}-2}$ & $\begin{array}{c}0.012 \\
(4.046)^{0}\end{array}$ & ${ }^{0.011}$ \\
\hline "i wages & $\begin{array}{c}0.017 \\
(5.198)\end{array}$ & $\begin{array}{c}0.067 \\
(5.471)\end{array}$ & $\begin{array}{c}0.089 \\
(8.450)\end{array}$ \\
\hline$"{ }_{i}$ & $\begin{array}{l}0.59 \mathrm{E}-3 \\
(0.966)\end{array}$ & $\begin{array}{l}0.34 \mathrm{E}-2 \\
(0.325)\end{array}$ & $\begin{array}{l}0.67 E-3 \\
(0.190)\end{array}$ \\
\hline$\left({ }^{i}{ }_{i i}\right.$ & $\begin{array}{c}-0.46 E-5 \\
(-1.199)\end{array}$ & $\begin{array}{c}-0.11 E-3 \\
(-2.068)\end{array}$ & $\begin{array}{c}-0.40 E-4 \\
(-4.511)\end{array}$ \\
\hline$"{ }^{i}{ }_{j}$ & $\begin{array}{l}0.86 \mathrm{E}-3 \\
(0.356)\end{array}$ & $\begin{array}{c}-0.74 E-2 \\
(-3.204)\end{array}$ & $\begin{array}{c}-0.011 \\
(-8.606)\end{array}$ \\
\hline$\left({ }^{i}{ }_{j j}\right.$ & $\begin{array}{l}0.18 E-5 \\
(2.040)\end{array}$ & $\begin{array}{l}0.92 E-5 \\
(2.441)\end{array}$ & $\begin{array}{l}0.17 E-4 \\
(4.221)\end{array}$ \\
\hline $2_{i}$ & $\begin{array}{l}-0.188 \\
(-0.649)\end{array}$ & $\begin{array}{c}5.753 \\
(4.442)\end{array}$ & $\begin{array}{c}4.893 \\
(8.193)\end{array}$ \\
\hline
\end{tabular}


TABLE 4. Demand Parameter Estimates

No Own Learning for A.V.C.

(t-statistics in parentheses)

\begin{tabular}{lc}
\hline & \\
\hline Parameter & Estimate \\
\hline${ }_{0}$ & -81.684 \\
& $(-2.115)$ \\
$0_{\mathrm{q}}$ & -0.727 \\
& $(-25.85)$ \\
$0_{\text {silk }}$ & 0.497 \\
& $(3.491)$ \\
$0_{\text {cotton }}$ & -0.157 \\
& $(-1.102)$ \\
$0_{\text {wool }}$ & 0.808 \\
& $(5.577)$ \\
$0_{\text {GNP }}$ & -0.839 \\
$0_{\mathrm{REG}}$ & $(-4.083)$ \\
$0_{J}$ & 0.738 \\
& $(6.312)$ \\
& 0.039 \\
& $(1.864)$ \\
\hline
\end{tabular}


TABLE 5. Pricing Relation Parameter Estimates No Own Learning for A.V.C. (t-statistics in parentheses)

\begin{tabular}{|c|c|c|c|}
\hline Parameter & A.V.C. & Dupont & $\operatorname{Six}$ \\
\hline$"{ }_{i}$ & $\begin{array}{l}-0.282 \\
(-2.877)\end{array}$ & $\begin{array}{l}-1.062 \\
(-2.576)\end{array}$ & $\begin{array}{c}-1.710 \\
(-5.065)\end{array}$ \\
\hline "i pulp & ${ }_{(2.891)^{0.24 E-2}}$ & $\begin{array}{l}0.012 \\
(3.847)^{0.012}\end{array}$ & ${ }^{0.96 \mathrm{E}-2}$ \\
\hline "i wages & $\begin{array}{c}0.019 \\
(9.983)\end{array}$ & $\begin{array}{c}0.070 \\
(5.860)\end{array}$ & $\begin{array}{c}0.091 \\
(8.882)\end{array}$ \\
\hline$"{ }_{i}$ & & $\begin{array}{l}0.14 \mathrm{E}-2 \\
(0.134)\end{array}$ & $\begin{array}{c}-0.10 E-2 \\
(-0.359)\end{array}$ \\
\hline$\left({ }^{i}{ }_{i i}\right.$ & & $\begin{array}{c}-0.10 E-3 \\
(-2.221)\end{array}$ & $\begin{array}{l}-0.44 \mathrm{E}-4 \\
(-5.597)\end{array}$ \\
\hline$"{ }^{i}{ }_{j}$ & $\begin{array}{l}-0.12 E-2 \\
-(4.884)\end{array}$ & $\begin{array}{c}-0.67 E-2 \\
(-3.059)\end{array}$ & $\begin{array}{c}-0.012 \\
(-9.578)\end{array}$ \\
\hline$\left({ }^{i}{ }_{j j}\right.$ & $\begin{array}{l}0.67 E-6 \\
(2.478)\end{array}$ & $\begin{array}{l}0.88 E-5 \\
(2.648)\end{array}$ & $\begin{array}{l}0.19 E-4 \\
(5.504)\end{array}$ \\
\hline $2_{i}$ & $\begin{array}{l}-0.018 \\
(-0.610)\end{array}$ & $\begin{array}{c}6.425 \\
(5.325)\end{array}$ & $\begin{array}{c}4.979 \\
(8.325)\end{array}$ \\
\hline
\end{tabular}




\section{REFERENCES}

Alchian, A. (1963). "Reliability of progress curves in airframe production," Econometrica, 31(4), 679-693.

Avram, M. (1929). The rayon industry. New York: D. Van Nostrand Company .

Boston Consulting Group, (1972). Perspectives on experience. Boston.

Bresnahan, T.F. (1989). "Empirical studies of industries with market power," In R. Schmalensee and R. Willig (eds.), Handbook of industrial organization, Vol II. Amsterdam: North-Holland.

Bulow, J., Geanakoplos, J., and Klemperer, P. (1985). "Multimarket oligopoly: strategic substitutes and complements," Journal of Political Economy, 93. 488-511.

Coleman, D.C. (1969). Courtaulds: An economic and social history, Vol. II, Rayon. London: Oxford University Press.

Fudenberg, D., and Tirole, J. (1983). "Learning by doing and market performance," Bell Journal of Economics, 14, 522-30.

Gallant, A.R., and Jorgenson, D.W. (1979). "Statistical inference for a system of simultaneous, non-linear, implicit equations in the context of instrumental variable estimation," Journal of Econometrics, 11, 275-302.

Ghemawat, P. and Spence, A.M. (1985). "Learning curve spillovers and market performance," Quarterly Journal of Economics, 100 (Supplement), 839-852.

Geroski, P.A. (1988). "In pursuit of monopoly power : Recent quantitative work in industrial economics," Journal of Applied Econometrics, 3, 107-123.

Hollander, S. (1965). The sources of increased efficiency: A study of DuPont rayon plants. Cambridge, MA: M.I.T. Press.

Jarmin, R.S. (1992). "Asymmetric learning spillovers," Mimeo, Center for Economic Studies, Bureau of the Census, Washington, D.C.

Lieberman, M.B. (1982). The learning curve, pricing, and market structure in the chemical processing industries. Ph.D. Dissertation, Harvard University, Boston. 
Lieberman, M.B. (1984). "The learning curve and pricing in the chemical processing industries," Rand Journal of Economics, 15, Summer, 213-228.

Markham, J. (1952). Competition in the rayon industry. Cambridge, MA: Harvard University Press.

Rapping, L. (1965). "Learning by experience as joint production," Quarterly Journal of Economics, 48(1), 81-86.

Roberts, M.J., and Samuelson, L. (1988) "An empirical analysis of dynamic, nonprice competition in an oligopolistic industry," Rand Journal of Economics, 19 Summer, 200-220.

Sheshinski, I. (1967). "Tests of the learning by doing hypothesis," Review of Economics and Statistics, 49 (4), 568-578.

Spence, A.M. (1981). "The learning curve and competition," Bell Journal of Economics, 12 (Spring) 49-70.

Temporary National Economic Committee, (1941).

"Investments, profits and rates of return for rayon companies." in Investigation of concentration of economic power, Part 31, Investments, profits and rates of return for selected industries. Washington.

Textile Economics Bureau. Textile Organon. Various issues.

U.S. Tariff Commission, (1946). The rayon industry. Washington.

U.S.D.A., Bureau of Agricultural and Industrial Chemistry.(1950) . Trends in the consumption of fibers in the United States, Statistical Bulletin, No. 89. Washington.

Wright, T.P. (1936). "Factors affecting the cost of airplanes," Journal of Aeronautical Sciences, $3(4), 122-128$. 


\section{ENDNOTES}

1. See Spence (1981) and Fudenberg and Tirole (1983) for the proprietary case and Fudenberg and Tirole (1983) and Ghemawat and Spence (1985) for the case with spillovers.

2. These include, among others, Wright (1936) and Lieberman (1982 and 1984).

3. A.V.C. held the U.S. rights to the important Cross and Bevan patents. This allowed it to maintain a monopoly until the patents expired in 1920.

4. The 8 largest firms included A.V.C., DuPont, the Industrial Fibre Corporation of America, the Tubize Artificial Silk Company of America, the Celanese Corporation of America, the American Bemberg Corporation, the North American Rayon Corporation and the American Enka Corporation.

5. During the sample period, rayon firms were primarily concentrated along the eastern seaboard.

6. Incumbents overinvest individually as compared to the static case with no learning. However, the industry underinvests in experience from a social welfare point of view (see spence, 1981 and Fudenberg and Tirole 1983). The strategic substitute terminology is due to Bulow, Geanakoplos and Klemperer (1985).

7. This choice is arbitrary. I also estimated the model where the dynamic effects which occur three of more periods into the future are captured in a firm specific constant. A Hausman test suggests the two alternatives do not produce significantly different results. Further, because it exploits more observations, the specification described in (6) produces more efficient estimates.

8. Because the constant term, " ${ }_{i}$, in each of the pricing relations is a composite, price-cost margins can only be estimated up to an unknown constant.

9. Data sources and computations are detailed in the appendix.

10. These include Celanese, Industrial Rayon, American Enka, American Bemberg, Tubize and North American. 